\title{
Biosocial variables and auditory acuity as risk factors for non-fatal childhood injuries in Greece
}

\author{
Eleni Petridou, Iosif Zervos, George Christopoulos, Katharine Revinthi, George \\ Papoutsakis, Dimitrios Trichopoulos
}

Center for Research and Prevention of Injuries, Department of Hygiene and Epidemiology, Athens, University Medical School, Athens, Greece and Department of Epidemiology, Harvard School of Public Health, Boston, Massachusetts, USA E Petridou

Center for Research and Prevention of Injuries, Department of Hygiene and Epidemiology, Athens University Medical School, Athens, Greece

I Zervos

G Papoutsakis

Pediatric Ear, Nose, and Throat

Department, Agia

Sophia Children's

Hospital, Athens,

Greece

G Christopoulos

Department of Epidemiology, Harvard School of

Public Health, Boston, Massachusetts, USA

D Trichopoulos

Correspondence to: Dr D Trichopoulos, Department of

Department of

School of Public Health, 677 School of Public Health, 677
Huntington Avenue, Boston Huntington Aven
MA 02115, USA.

Reprint requests to: Dr E Petridou, Center for Research and Prevention of Injuries, Department of Hygiene and Epidemiology, Athens University Medical School, 75 M Asias Str, Goudi, Athens 11527 , Greece.

\begin{abstract}
Objectives-To examine whether biosocial variables and auditory acuity are risk factors for injuries among children.

Setting-Children with injuries who presented at the emergency clinics of one of the two university hospitals for children in Athens, Greece between December 1993 and April 1994.
\end{abstract}

Methods-144 children aged 5-14 years, residents of Athens, were brought to the emergency clinics for a moderate to severe injury. For each of these children one hospital control, matched for age and sex, and one classmate control similarly matched were identified. A standard interview form was completed for all 432 children and acouometric and tympanometric examinations were performed in each of them. Analysis was done through conditional logistic regression.

Results-The likelihood of an accident was higher in children of younger fathers (odds ratio $(O R)=0.7, p=0.04$ ), children of mothers with non-professional jobs $(O R=1.9, p=0.03)$ as well as in children of higher birth order $(O R=1 \cdot 7, p=0.01)$, in those with predominantly other than parental daily supervision $(O R=2 \cdot 6$, $p=0.001$ ), and those with a history of previous accident $(O R=1 \cdot 3, p=0.002)$. Somatometric factors, school performance, use of corrective eyeglasses and subnormal auditory acuity were not found to be risk factors, but auditory imbalance and abnormal tympanograms were positively related to the risk of childhood injury $(O R=2.6, p=0.02$; and $\mathrm{OR}=2 \cdot 3, p=0.08$ respectively).

Conclusions-the findings of this study underline the importance of attentive supervision and safety training of children living in modern cities; they also suggest that children with auditory imbalance and history of an accident are at higher injury risk and they should be targeted with specific intervention programs.

(Injury Prevention 1995; 1: 92-96)

Keywords: biosocial variables, auditory acuity, risk factors.

The changing spectrum of childhood morbidity and mortality in developed countries has made injury the main cause of premature disability and death. ${ }^{1-11}$ Epidemiological studies in several countries have mostly focused on road traffic injuries as well as domestic and school injuries. ${ }^{12-24}$ However, it is also important to study injuries of any type as a whole in order to identify underlying biological or sociodemographic characteristics that may predispose to their occurrence. Specific categories of injuries may have their own etiological components but a generalized vulnerability is also likely to be present as, for instance, poverty underlies the whole spectrum of human nosology and immunological breakdown increases the risk of several distinct infectious diseases. In Greece, childhood mortality from injuries has sharply increased over the last 30 years not only in relative but also in absolute terms, ${ }^{11}$ in contrast to the situation in most European Union countries in which an absolute decline has been observed during the most recent period. In the context of a national program for childhood injury prevention, we have undertaken a case-control study in Athens, Greece to examine the importance of sociodemographic variables and sensory organ acuity as risk factors for non-fatal childhood accidents. Sociodemographic variables have been reported as risk factors for childhood injuries in several, but not all, studies undertaken in different population groups. Moreover sensory integrity is a prerequisite for optimal adaptation to changing environmental conditions, and injuries represent an important consequence of an acute failure of adaptive response. The study did not focus on circumstances and physical conditions at the time and place of the accident or on triggering events. Examination of the importance of the latter factors requires different methodological approaches which are currently being pursued. ${ }^{2526}$

\section{Subjects and methods}

Between December 1993 and April 1994 one of us (IZ) was present for a total of 75 nonconsecutive days and for about three hours per day at the emergency clinics of 'Aghia Sophia' Children's Hospitals, one of two major university hospitals for children in Athens. During this period, a total of 157 schoolchildren aged 5-14 years, residents of the Greater Athens area, were brought to the clinics after an accident. The schools of these children were identified and one control child exactly matched for school, age (single year), and gender was randomly selected for every child with injury from the respective class rosters. In addition, a second control series was generated from children who were brought to the hospital 
for a reason other than injury or ear, nose, and throat ailment; these control children were also individually matched to the index children on age (single year), gender, and date of hospital contact. A standardized form was completed for the cases and hospital controls by the children and their guardians (mothers in $82 \%$ of case and $84 \%$ of hospital controls) or by children and their families in collaboration with their teachers for the schoolmate controls. The forms covered somatometric and sociodemographic variables concerning the children and their families. For every participating child a standard acouometric examination was performed by the same pediatric ear, nose, and throat physician (IZ) using a portable diagnostic audiometer (model AD27, Interacoustics) which meets the standards set by the American National Standards Institute (ANSI). The acouometric variables in the present study were: the mean-over the two ears-auditory threshold characterization, and the auditory imbalance defined as the absolute difference in auditory acuity expressed in decibels (dB) between the two ears. Moreover, a tympanogram was obtained for every child. The protocol was approved by the Hospital Committee on Biomedical Research and the Ministry of Education. Informed consent was obtained from the parents or legal guardians of the children. There were eight refusals from the cases or their guardians and 10 from the hospital control children or their guardians. The index cases for which no classmate control was available were excluded from the analysis, whereas 10 additional hospital controls were substituted for those who had refused to participate or were unable to cooperate. The teachers of five injured children did not cooperate for the selection of classmate controls and these were also excluded. Therefore, the final analysis was based on 144 matched triplets, that is 144 cases and 288 control children.

The statistical analysis was done originally through univariate stratification of cases and controls and subsequently through conditional logistic regression. ${ }^{27}$ Conditional logistic re-

Table 1 Distribution of 144 injured children by place, mechanism, and severity of injury

\begin{tabular}{lc}
\hline & No $(\%)$ \\
\hline Place of injury & \\
Playground & $51(35)$ \\
Athletic field, sport & $33(23)$ \\
Living room, bedroom & $14(10)$ \\
Transportation & $9(6)$ \\
Kitchen & $7(5)$ \\
Driveway & $7(5)$ \\
Educational building & $6(4)$ \\
Stairs & $4(3)$ \\
Disco and amusement & $4(3)$ \\
Other and unspecified & $9(6)$ \\
Mechanism & \\
Struck, hit, collision & $54(38)$ \\
Fall on same level & $54(38)$ \\
Fall from higher level & $13(9)$ \\
Cutting, piercing & $9(6)$ \\
Strain & $5(3)$ \\
Jammed, pinched & $4(3)$ \\
Other and unspecified & $5(3)$ \\
Severity & \\
Hospitalized & $31(22)$ \\
Not hospitalized & $113(78)$ \\
\hline
\end{tabular}

gression is tailored to matched case-control designs and is the only type of analysis that allows both preservation of matching and control for additional, non-matched for, confounding variables. A separate conditional logistic regression contrasting the two control series revealed no substantial or plausible differences; therefore the two control series were combined in all subsequent analyses. The categories used in the regression modelling are shown in table 1 . For height, the standard centiles developed by the ' $A$ ' Pediatric Department of the University of Athens were used, ${ }^{28}$ whereas the body mass index was calculated as weight over the square of height and then distributed in marginal (combined) empirical quintiles. School performance was assessed in three categories on the basis of the overall performance of the child in the previous academic year or the teacher's opinion for very young children. The daily supervision was considered as mostly parental when at least one of the parents was usually at home during the non-school hours of the day; children of single parent families were considered as having other than mostly parental supervision. Previous accidents were considered only those that required hospital outpatient contact. Average auditory acuity was considered as reduced when the threshold was increased by five or more decibels whereas tympanometric findings were classified as either normal (type A) or abnormal (types B and C). ${ }^{29}$ In the conditional logistic regression analysis, age and gender were inherently controlled as they were matching variables; the other predictor characteristics were introduced either in terms of categories (maternal occupation, body mass index, daily supervision, use of corrective eyeglasses, and tympanometric findings) or as grouped ordered variables with incremental units shown in table 2. Choice between the ordered or categorical approach was based on assumption or empirical evidence for the existence of a monotonic log linear trend or otherwise.

\section{Results}

Of the 144 injuries, 36 took place at home, 54 at school mostly during breaks, 31 during sporting activities, nine during transportation, and 14 elsewhere. The predominantly inflicted body part was head for 75 children, hands for 42 , legs for 21 , and main body for only six of them. Among the injured children 16 had predominantly bone fractures, 46 joint dislocation and sprains, whereas 34 had open wounds, 21 injuries to blood vessels or nerves and $27 \mathrm{had}$ injuries of lesser severity. Other aspects of injuries in the study subjects are summarized in table 1.

Table 2 shows the distribution of injured children and their age and gender matched controls by the study variables, as well as two tailed $\mathrm{p}$ values corresponding to crude $\chi^{2}$ tests for contrast or linear trend. This table serves descriptive purposes and allows characterization of the study subjects in terms of the variables under consideration. However, the 
Table 2 Distribution of 144 injured children and their 288 age and gender matched controls by the study variables

\begin{tabular}{|c|c|c|c|}
\hline Variable & No $(\%)$ cases & No $(\%)$ controls & $\begin{array}{l}p \text { Value for } \\
\text { contrast or } \\
\text { linear trend }\end{array}$ \\
\hline $\begin{array}{l}\text { Age (in years) } \\
5-9 \\
10-14\end{array}$ & $\begin{array}{l}54(37.5) \\
90(62.5)\end{array}$ & $\begin{array}{l}104(36 \cdot 1) \\
184(63.9)\end{array}$ & $\begin{array}{c}\text { Matched } \\
\text { variable }\end{array}$ \\
\hline $\begin{array}{l}\text { Gender } \\
\text { Male } \\
\text { Female }\end{array}$ & $\begin{array}{l}94(65 \cdot 3) \\
50(34 \cdot 7)\end{array}$ & $\begin{array}{l}188(65 \cdot 3) \\
100(34 \cdot 7)\end{array}$ & $\begin{array}{c}\text { Matched } \\
\text { variable }\end{array}$ \\
\hline $\begin{array}{c}\text { Paternal age } \\
\leqslant 34 \\
35-39 \\
40-44 \\
45-49 \\
50+\end{array}$ & $\begin{array}{c}9(6 \cdot 3) \\
52(36 \cdot 1) \\
48(33 \cdot 3) \\
21(14 \cdot 6) \\
14(9 \cdot 7)\end{array}$ & $\begin{array}{r}24(8 \cdot 3) \\
73(25 \cdot 3) \\
103(35 \cdot 8) \\
57(19 \cdot 8) \\
31(10 \cdot 8)\end{array}$ & 0.21 \\
\hline $\begin{array}{c}\text { Maternal age } \\
\leqslant 29 \\
30-34 \\
35-39 \\
40-44 \\
45+\end{array}$ & $\begin{array}{l}11(7 \cdot 6) \\
41(28 \cdot 5) \\
52(36 \cdot 1) \\
29(20 \cdot 2) \\
11(7 \cdot 6)\end{array}$ & $\begin{aligned} 18(6 \cdot 2) \\
84(29 \cdot 2) \\
112(38 \cdot 9) \\
52(18 \cdot 1) \\
22(7 \cdot 6)\end{aligned}$ & 1.00 \\
\hline $\begin{array}{l}\text { Maternal occupation } \\
\text { Housewife } \\
\text { Professional } \\
\text { Other }\end{array}$ & $\begin{array}{l}46(31.9) \\
14(9 \cdot 7) \\
84(58.4)\end{array}$ & $\begin{array}{r}110(38 \cdot 2) \\
36(12 \cdot 5) \\
142(49 \cdot 3)\end{array}$ & $\begin{array}{l}\text { Referent } \\
0.84 \\
0.12\end{array}$ \\
\hline $\begin{array}{l}\text { Sibship size } \\
1 \\
2 \\
3+\end{array}$ & $\begin{array}{c}12(8 \cdot 3) \\
105(72 \cdot 9) \\
27(18 \cdot 8)\end{array}$ & $\begin{array}{c}25(8 \cdot 6) \\
192(66 \cdot 7) \\
71(24 \cdot 7)\end{array}$ & 0.32 \\
\hline $\begin{array}{l}\text { Birth order } \\
1 \\
2 \\
3+\end{array}$ & $\begin{array}{l}66(45 \cdot 8) \\
59(41.0) \\
19(13 \cdot 2)\end{array}$ & $\begin{array}{c}134(46 \cdot 5) \\
130(45 \cdot 2) \\
24(8 \cdot 3)\end{array}$ & 0.41 \\
\hline $\begin{array}{l}\text { Height (centiles) } \\
\leqslant 25 \\
26-50 \\
51-75 \\
76+\end{array}$ & $\begin{array}{l}28(19.4) \\
59(41 \cdot 0) \\
35(24.3) \\
22(15 \cdot 3)\end{array}$ & $\begin{array}{r}54(18 \cdot 8) \\
113(39 \cdot 2) \\
75(26 \cdot 0) \\
46(16 \cdot 0)\end{array}$ & 0.70 \\
\hline $\begin{array}{l}\text { Body mass index (er } \\
\text { 1st (lower) } \\
2-4 \\
5 \text { th (higher) }\end{array}$ & $\begin{array}{l}26(18 \cdot 1) \\
88(61 \cdot 1) \\
30(20 \cdot 8)\end{array}$ & $\begin{array}{r}62(21.5) \\
168(58 \cdot 4) \\
58(20 \cdot 1)\end{array}$ & 0.80 \\
\hline $\begin{array}{l}\text { School performance } \\
\text { A (good) } \\
\text { B } \\
\text { C (poor) }\end{array}$ & $\begin{array}{l}71(49 \cdot 3) \\
58(40 \cdot 3) \\
15(10 \cdot 4)\end{array}$ & $\begin{array}{c}139(48 \cdot 2) \\
122(42 \cdot 4) \\
27(9 \cdot 4)\end{array}$ & 1.00 \\
\hline $\begin{array}{l}\text { Daily supervision } \\
\text { Mostly parental } \\
\text { Mostly other }\end{array}$ & $\begin{array}{r}44(30 \cdot 6) \\
100(69 \cdot 4)\end{array}$ & $\begin{array}{l}118(41.0) \\
170(59.0)\end{array}$ & 0.04 \\
\hline $\begin{array}{l}\text { Previous accident(s) } \\
\text { None } \\
1-4 \\
5+\end{array}$ & $\begin{array}{l}48(33.3) \\
74(51 \cdot 4) \\
22(15 \cdot 3)\end{array}$ & $\begin{array}{c}114(39.6) \\
164(56.9) \\
10(3.5)\end{array}$ & 0.003 \\
\hline $\begin{array}{l}\text { Corrective eyeglasse } \\
\text { No } \\
\text { Yes }\end{array}$ & $\begin{array}{r}119(82 \cdot 6) \\
25(17 \cdot 4)\end{array}$ & $\begin{array}{r}240(83 \cdot 3) \\
48(16 \cdot 7)\end{array}$ & 0.86 \\
\hline $\begin{array}{l}\text { Auditory acuity } \\
\text { Normal } \\
\text { Reduced }\end{array}$ & $\begin{array}{c}132(91 \cdot 7) \\
12(8 \cdot 3)\end{array}$ & $\begin{array}{c}270(93.8) \\
18(6.2)\end{array}$ & 0.40 \\
\hline $\begin{array}{l}\text { Absolute difference } \\
\text { (dB) } \\
0 \\
10 \\
20+\end{array}$ & $\begin{array}{c}135(93 \cdot 8) \\
2(1 \cdot 4) \\
7(4 \cdot 8)\end{array}$ & $\begin{array}{c}283(98.3) \\
2(0 \cdot 7) \\
3(1 \cdot 0)\end{array}$ & 0.01 \\
\hline $\begin{array}{l}\text { Tympanogram } \\
\text { Type A (normal) } \\
\text { Types B and C }\end{array}$ & $\begin{array}{r}125(86 \cdot 8) \\
19(13 \cdot 2)\end{array}$ & $\begin{array}{r}258(89 \cdot 6) \\
30(10 \cdot 4)\end{array}$ & 0.39 \\
\hline
\end{tabular}

existence of mutual confounding does not allow conditional statements and etiologic inferences. Table 3 presents the results of modelling through conditional logistic regression. The odds ratios in this table are mutually adjusted and are therefore directly interpretable. The likelihood of an accident is higher in children of younger parents as reflected in paternal age. Conditional on parental age however, maternal age has no significant association with the risk of injuries in children. Moreover, the risk of injury is higher in families in which the mother is either a professional or has another outside job, rather than being a housewife, although the odds ratio is significantly raised only with respect to mothers with non-professional occupations. It is of interest that the maternal occupation association persists even after accounting for the predominant type of daily supervision. Children of higher birth order are at a substantially and significantly increased risk, whereas sibship size has no independent effect after controlling for birth order. However, as higher birth orders require a large sibship size, the latter is still a predictor of childhood injury, when birth order is not accounted for in the analysis. History of a previous injury requiring hospital outpatient contact is also a significant risk factor for a subsequent injury. Somatometric factors, school performance, and use of corrective eyeglasses are not risk factors for childhood injuries in this dataset, nor is subnormal auditory acuity. By contrast, auditory imbalance and abnormal tympanograms are positively and significantly related to the risk of childhood injury.

\section{Discussion}

In the Greater Athens area childhood emergency care, including care for childhood injuries, is mainly provided by two university hospitals for children on alternating days throughout the year. Therefore, although the present study was hospital based it had adequate population coverage of incident cases of childhood injuries during the time window of the study. Fatal cases and cases not requiring hospital contact were not included; we estimate that there should be between four and eight fatal cases during the time period of the study, a number too small to generate substantial selection bias in the results. There were many more accidents not requiring hospital contact, but this category of accidents does not represent a problem of similar public health severity. The similarity between the two control series and the recruitment of control subjects from study populations reasonably representative of the underlying study base $e^{3031}$ provides further assurance for the comparability of the case and the combined control series. To the extent that the odds ratio in all case-control studies of new cases evaluates the incidence density ratio, controls who have had injuries in the past should not be and were not excluded. ${ }^{30}$ The study was of moderate size, but the matched design and the conditional regression analysis have generated sufficient power for associations of modest strength.

It has been reported that young maternal age increases the probability of a childhood accident. ${ }^{32}$ In the Greek sociocultural environment parental age is best reflected in paternal age; therefore, our finding that paternal age is inversely related to the risk of childhood accident does not contradict the earlier report. The protective impact of mostly parental daily supervision and of maternal work as housewife may be accounted for by both closer supervision and more effective modulation of safety 
Table 3 Multiple conditional logistic regression derived odds ratio estimates (and 95\% confidence intervals) for childhood injury, associated with a series of potential risk factors

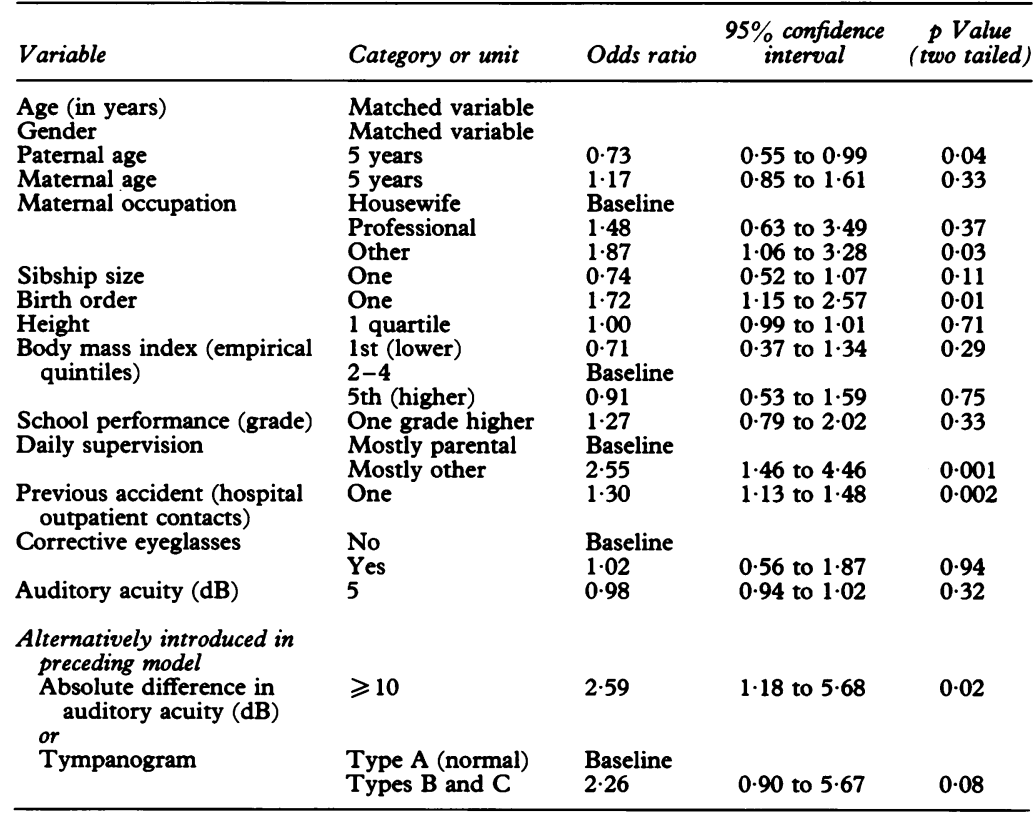

promoting behavior. ${ }^{33-35}$ The higher odds ratio for injuries among children of mothers in non-professional occupations reflects the well known disadvantage of lower socioeconomic groups. ${ }^{14}{ }^{1935-39}$ In this study, as in previous ones, ${ }^{1940}$ high birth order was associated with higher risk of injury, probably because an increased need for attention on account of young age cannot be met by an overextended guardian. Several earlier studies ${ }^{1941}$ as well as the present one suggest that children with a history of previous injury are at increased risk for another injury. It appears that history of a previous injury can be used for the identification of a group of susceptible children to whom injury prevention programs should be targeted.

In this data there was no evidence that overweight children with suboptimal fitness, those using corrective glasses, and those with a mild auditory deficit were at increased risk for an accident. It appears that although extreme impairment of physiological functions is likely to increase the risk for injuries, chronic subnormal or mild deviations are well compensated. By contrast, unilateral hearing loss reflected in absolute difference in auditory acuity of 10 or more decibels imparts a small but statistically significant and clinically relevant excess risk. It may be that the complex orientation process is adversely affected by unbalanced auditory stimulation. Consideration of biological characteristics should be integrated with other factors that affect exposure and response to situations with elevated injury risk. These factors and their interaction have been critically overviewed in the injury literature. ${ }^{42}$

In conclusion, the findings of the present study underline the importance of supervision and safety training of young children facing the increasingly hazardous environment of the modern city life style; they suggest that auditory imbalance increases injury risk; and they indicate that children with a history of accident are at higher risk to sustain a new injury and should be prime targets for injury prevention programs.

This study was supported by a grant from the Consumer Policy Service of the European Union and was conducted in association with the European Home and Leisure Activities Surveillance System (EHLASS) in Greece.

1 Bass JL, Mehta KA, Eppes BM. What school children need to learn about injury prevention. Public Health Rep 1989; 104: 385-8.

2 Christophersen ER. Injury control. American Psychologist 1989; 44: 237-41.

3 Vimpani G. Injury surveillance: a key to effective control of childhood injuries. Australian Paediatric fournal 1989; 25: $10-3$.

4 Wheatley J, Cass DT. Traumatic deaths in children: the importance of prevention. Med $\mathcal{F}$ Aust 1989; 150: 72-8.

5 Guyer B, Ellers B. Childhood injuries in the United States. Mortality, morbidity, and cost. Am $\mathcal{F}$ Dis Child 1990; 144: 649-52.

6 Macarthur C, Pless IB. Unintentional injury mortality in Canada. Pediatrics 1990; 86: 1073-7.

7 Rosenberg ML, Rodriguez JG, Chorba TL. Childhood injuries: where we are. Pediatrics 1990; 86: 1084-91.

8 Williams BC, Kotch JB. Excess injury mortality among children in the United States: comparison of recent children in the United States: comparison of recent

9 Bergman AB, Rivara FP. Sweden's experience in reducing childhood injuries. Pediatrics 1991; 88: 69-74.

10 Jones NE. Childhood injuries: an epidemiologic approach. Pediatric Nursing 1992; 18: 235-9.

11 World Health Organization. World health statistics annual, 1992. Geneva: WHO, 1993.

12 Guyer B, Gallagher SS, Chang BH, Azzara CV, Cupples LA, Colton T. Prevention of childhood injuries: evaluation of the Statewide Childhood Injury Prevention Program (SCIPP). Am $\mathcal{F}$ Public Health 1989; 79: 1521-7.

13 Hausel $M$, Huber $M$. Analysis of accidents in children in school, apprenticeship and agriculture. Unfallchirurgie 1989; 15: 269-72.

14 Pless IB, Verreault R, Tenina S. A case-control study of pedestrian and bicyclist injuries in childhood. Am $\mathcal{F}$ Public Health 1989; 79: 995-8.

15 Thompson RS, Rivara FP, Thompson DC. A case-control study of the effectiveness of bicycle safety helmets. $N$ Engl 7 Med 1989; 320: $1361-7$.

16 Sahlin Y, Stene TM, Lerein I, Balstad P. Occurrence of injuries in a defined population. Injury 1990; 21: 155-7.

17 Baudier F, Marchais M, Bourderont D, Pierot G, Pinochet C, Laroze $M$. Cooperative program for domestic accidents of children in the department of Doubs. Epidemiological aspects. Arch Fr Pediatr 1988; 45: 423-7.

18 Sheps SB, Evans GD. Epidemiology of school injuries: a 2-year experience in a municipal health department. Pediatrics 1987; 79: 69-75.

19 Bourguet CC, McArtor RE. Unintentional injuries. Risk factors in preschool children. Am $\mathcal{f}$ Dis Child 1989; 143: 556-9.

20 Chang A, Lugg MM, Nebedum A. Injuries among preschool children enrolled in day-care centers. Pediatrics 1989; 83: 272-7.

21 Bergman E, Bjornstig U. School injuries. Epidemiology and clinical features of 307 cases registered at hospital during 209-16.

22 Schelp I, Ekman R, Fahl I. School accidents during a three school-years period in a Swedish municipality. Public Health 1991; 105: 113-20.

23 Lenaway DD, Ambler AG, Beaudoin DE. The epidemiology of school-related injuries: new perspectives. Am $\mathcal{F}$ Prev Med 1992; 8: 193-8.

24 Gratz RR. School injuries: what we know, what we need. Journal of Pediatric Health Care 1992; 6: 256-62.

25 Brown BP, Salmi LR, Lecours S, Battista RN. Motor vehicle related injury on the bridges between Montreal and the South Shore of the St Lawrence River, 1978-82. Am 7 Public Health 1985; 75: 871-4.

26 Maclure $M$. The case-crossover design: a method for studying transient effects on the risk of acute events. $A m \mathcal{F}$ Epidemiol 1991; 133: 144-53.

27 Breslow NE, Day NE. Statistical methods in cancer research. Vol I. The analysis of case control studies. IARC Scientific Publication 32. Lyon: IARC, 1980.

28 Dacou-Vouketakis C, Lagos P, Papathanasiou-Clontza D. Height and weight in Greek pupils $6-18$ years. In: Eveleth $\mathrm{P}$, Tanner J eds. World wide variations of human growth. Cambridge: Cambridge University Press, 1991.

29 Carhart $R$. Measurement of hearing. In: Paparell MM, Shunrick DA, eds. Otolaryngology. Vol I. Philadelphia: WB Saunders, 1973: 967-85.

30 Miettinen OS. Theoretical epidemiology: principles of occurrence research in medicine. New York: John Wiley, 1985.

31 Walker AM. Observation and inference: an introduction to the methods of epidemiology. Boston: Epidemiology Resources Inc, 1991 . 
32 Jordan EA, Duggan AK, Hardy JB. Injuries in children of adolescent mothers: home safety education associated with decreased injury risk. Pediatrics 1993; 91: 481-7.

33 Peterson L, Ewigman B, Kiulahan C. Judgements regarding appropriate child supervision to prevent injury: the role of environmental risk and child age. Child Dev 1993; 64: 934-50.

34 Santer LJ, Stocking CB. Safety practices and living conditions of low-income urban families. Pediatrics 1991; 88: $112-8$.

35 Carey V, Vimpani G, Taylor R. Childhood injury mortality in New South Wales: geographical and socioeconomic variations. F Paediatr Child Health 1993; 29: 136-40.

36 Registrar General for England and Wales. Occupational mortality 1970-1972. OPCS Series DS No I. London: HMSO, 1978.
$37 \mathrm{Hsu}$ JS, Williams SD. Injury prevention awareness in an urban Native American population. Am $\mathcal{F}$ Public Health 1991; 81: 1466-8.

38 Santer LJ, Stocking CB. Safety practices and living conditions of low-income urban families. Pediatrics 1991; 88: $1112-8$.

39 Gofin $\mathbf{R}$, Lison $\mathbf{M}$, Morag $C$. Injuries in primary care practices. Am $\mathcal{f}$ Dis Child 1993; 68: 223-6.

40 Elliott BA. Birth order and health: major issues. Soc Sci Med 1992; 35: 443-52.

41 Petridou E, Kouri N, Trichopoulos D, Revinthi K, Skalkidis $Y$, Tong $D$. School injuries in Athens: socioeconomic and family risk factors. 7 Epidemiol Community Health 1994; 48: 490-1.

42 Grossman DC, Rivara FP. Injury control in childhood. Pediatr Clin North Am 1992; 39: 471-85.

From Dr Hugh Jackson, President of the Child Accident Prevention Trust

In 1950, when I was a registrar in the children's wards at the Royal Victoria Infirmary, Newcastle on Tyne, two brothers of about 11 and 9 were admitted late one evening with what seemed to be second degree burns of their legs and to a lesser extent of their arms.

It was a curious story. They lived on a farm in Northumberland, and earlier in the day they had been playing in a young forest plantation nearby. In a clearing in the forest they found an empty, open, dark green wine bottle which they set up at one end of the clearing, and threw stones at it from the other end. When it broke, nothing came out, and they then began to go home for tea. On the way home they both began to feel a burning sensation on their legs, so much so that they took their shoes and socks off and washed their legs in a stream. When they got home their mother immediately questioned them as to what they had been up to, and what was the funny smell they had about them. She took all their clothes off and washed them, and bathed the boys and put them to bed. During the evening the burns got worse, and the family doctor was sent for and he referred them to hospital.

The only way I could account for the blisters and reddening was that the bottle could have contained mustard gas - but how to prove it?

A few days later, when the elder boy was better, he told me that he thought he could find the clearing again, so that when I came off duty I went with him to find the broken glass. I put a wooden box in the boot of the car, plus wellington boots, a pair of long fire tongs, and some old motorcycling gauntlets. In the dusk we found the clearing and with a torch found the broken bottle. Some of the bits had one or two brown sticky-looking blots of material a few millimetres in diameter, and I could smell the smell the mother had complained of. So, back to the hospital.

Next day I took the box containing the glass into the university, where it was proved that the material on the glass was indeed mustard gas. How the mustard gas came to be in a wine bottle in a forest in Northumberland remains a mystery. The army sent a detachment to search the area further, but found nothing. During the war there had been a Polish Army camp somewhere in the area, but it was thought unlikely that they would either have mustard gas or that it would get into a wine bottle.

A lesson I learnt is how dangerous this poisonous substance can be. After all, it had been in an open bottle for at least five years, and the boys had been at least 20 metres away from it when it broke-and yet they still received the burns. 